AC 2007-1450: AN ASSESSMENT OF PERFORMANCE AND LEARNING EXPERIENCE OF STUDENTS IN A DISTANCE-LEARNING PROGRAM

Keshav Varde, University of Michigan-Dearborn 


\title{
An Assessment of Performance and Learning Experience of Students in a Distance Learning Program
}

\begin{abstract}
The easy access and efficiency of internet have led to an explosive growth in educational programs offered via distance learning or asynchronous modes. While such programs provide opportunities for students and professionals to advance their education and complete their educational aspirations there have been criticisms on the quality of education and value-added knowledge gained by students. The College of Engineering and Computer Science at this institution has been offering several graduate degree programs via AL learning mode; these programs are identical to those offered to on-campus students. This provided an opportunity to assess and compare performance and learning outcomes of AL Vs on-campus students.

This assessment was based on two graduate level courses which had a combined enrollment of over 150 graduate students. While the quality of instruction and knowledge transfer to both the groups was about the same, academic assessment of the two groups showed following characteristics:
\end{abstract}

1. Although AL students, on average, performed as well as the campus students, the spread in their performance was larger than the campus students.

2. Self-discipline and time management seemed to be some of the major factors contributing to larger standard deviation in various performance categories.

3. The top three quartile of AL students were as well educated and had almost equal learning experience with their counterparts but the last quartile of AL students struggled more than the campus students.

4. Both the groups were well-equipped to handle technology, including the use of computer software to do projects and assignments.

5. On average, the instructor had to devote much more time to AL students' learning and comprehension than the campus students.

This paper discusses these and other findings that would help AL program planners and instructors to devote appropriate resources to distance or asynchronous learning programs.

\section{Introduction}

The need to serve educational needs of working professionals and advances in computer and multimedia technology have led colleges, universities and many professional societies and forprofit organizations to offer a suite of programs ranging from customized courses to undergraduate and graduate degree programs. In the last decade or so there has been a continued growth in this arena using on-line or distance learning (DL) or asynchronous learning (AL) programs. 
While such an explosive growth in programs provides a wonderful opportunity for students and professionals to advance their educational experience critics claim that the quality of education and value-added knowledge gained by students is lower than the on-campus programs. In addition, there have been claims that the quality of incoming and outgoing students in the DL or AL programs is lower than the corresponding quality of on-campus students. Some of these criticisms have outright insinuated that students in AL programs get inferior education than the on-campus students. The assessment of DL or AL programs has been the subject of several investigations. Chapman ${ }^{1}$ has addressed reasons for developing an evaluation plan for online degree program. A report by Indiana University's team on educational research considered "Technology as a Lever" in developing guideline for good practice in education ${ }^{2}$. These and other investigators have focused on assessment of on-line or DL courses and programs. But comparisons of performance of on-campus and DL or AL students have been rare. Johnson et $\mathrm{al}^{3}$ compared learning outcomes and learner satisfactions of on-campus and on-line students. But their comparison was based on two distinct groups of students, one involved in on-campus courses while the other in on-line courses. Furthermore, their paper focused on rating instructor and course quality, learning support, course grades, etc. Varde and Fogler ${ }^{4}$ reported results of their on-line course that included all students in the on-line section. A preliminary report on the performance of distance learning students in a graduate course was presented by Varde ${ }^{5}$. But not much has been reported that involves comparison of students' performance and instructional issues in a course or program that includes face-to-face instruction to a portion of students and AL mode instruction to another group of students in the same course or program. This paper deals with student learning in a set of courses that included face-to-face or on-campus students as well as distant or AL mode learners.

\section{Requirements and design of asynchronous programs}

The College of Engineering and Computer Science (CECS) at our campus serves educational needs of a large number of practicing engineers in the area by offering graduate degree programs, graduate certificate programs and specialized short courses and seminars. The need to offer AL programs was brought up by several interested parties including the college administration, the advisory board and the industrial stakeholders. They insisted that increasing globalization of engineering design and manufacture necessitates constant movement and relocation of engineers within and outside the country and the educational needs of these professionals would well be served by offering AL programs that complement the existing oncampus graduate programs.

Following prolonged discussions and debates, the College decided to offer a select number of graduate programs via AL mode. To ensure the quality of AL program admits met the standards and that the instructional activities mirrored with those of the on-campus programs, the College adopted the following guidelines:

- The applicant was not asked to select on-campus or AL program, a priori, thereby maintaining the application process and academic credentials of all applicants transparent to the admissions committees.

- The courses offered through AL mode could not be different that those offered to oncampus students that semester. The number of AL courses could be less depending on the availability of special classrooms that were needed for AL activities. 
- The instructor teaching the on-campus course should also be involved in the AL mode of the course that semester thus removing variability in instructional activities as much as possible.

- All students (on-campus and AL) were to be evaluated and graded on the same basis thereby allowing no differentiation between the output quality of on-campus and AL students.

- The students in the programs could freely elect on-campus or AL mode courses any semester, as desired.

- All instructors involved with AL courses were expected to schedule virtual office hours to cater to academic needs of AL students.

These guidelines were implemented and practiced through the design of AL mode courses and requirements, as described below:

- Each course offered via AL mode was designated as second section of the on-campus course and the students could elect one of the two sections depending on the preference. The same instructor handled both the sections.

- The College developed its own AL infrastructure with custom-designed website and a dedicated server that could handle a large number of students at any given moment. The instructors posted their instructional and course related material (course syllabus, course calendar, lecture notes, assignments, practice problems, etc.) on the site; the course site could be accessed only by students registered in the course. They could download notes, assignments, etc. and upload their assignments or projects, as needed.

- The course site allowed the instructor to post common or individualized messages to students delivered via their e-mail addresses. Likewise, the students could post question to the instructor or as a discussion topic for all students in the course.

- The on-campus section was automatically recorded (video and audio portions) during live presentation and the recording was made available to AL students, via edited streaming videos, in a day. This feature provided "delayed access to classroom activities", in a sense, to all AL students that semester.

- The engineering honor pledge system was enforced on all graded assignments, quizzes, projects and tests.

- The AL students were free to take tests on campus with on-campus students or they could arrange to take tests at pre-designated sites and pre-designated times, through prior arrangements with the College's AL program coordinator. All tests, whether on campus and at remote sites, were proctored.

- In addition to on-campus office hours all instructors maintained virtual office hours, the length of which depended on the number of students registered in the AL section of the course.

The design and implementation of the AL programs, with features described above, alleviated many of the problems encountered in asynchronous learning programs. It also allowed a 
comparative assessment of issues related to teaching of and learning by AL students and assessment of on-campus and AL mode students.

3. Teaching, communications and learning issues

The author of this paper has been involved in teaching several graduate courses in the programs that include on-campus and AL students. This paper deals with issues pertaining to teaching for and learning by graduate students in the AL section and their performance in the course in various categories relative to on-campus students in the same courses. The analysis is based on a sequence of two graduate level courses (course 1 and 2) that this author taught to on-campus and AL students over a period of three years and covered about 156 students. Course 2 requires course 1 as a prerequisite. The students enrolled in course 2 were more interested in the subject matter and had done well in course 1. It is also considered as a higher level course compared to course 1 . About $32 \%$ of the students monitored for this project were registered as AL students while the rest were on-campus students. This provided a good mix of students for evaluation purposes. A significant portion of AL students were from the area but elected to be in the AL section due to commute, frequent business travel, time management problems and out-of-town relocation for an extended period of time.

\subsection{Student differences}

There were no distinct differences between the on-campus and AL students. Most of the students in both the groups had graduated from college within the last seven years with undergraduate degrees in engineering (mechanical or electrical). The admissions requirements for both the groups were identical and provided the basis that undergraduate academic credentials of all students were similar, within a range. The major difference noticed was in the third year of course 1; there were a higher percentage of international students in the on-campus section of the course than the two previous years. The AL students were provided with all the needed information on computer requirements and internet connection. The students did not seem to encounter any issues related to computer technology, access to our website and downloading notes and streaming videos. Except for the differences noted above, the two groups were comparable in their academic background, years since graduation, etc.

\subsection{Teaching related issues}

Course notes, organized in sequential format and divided into chapters and sections according to planned coverage of material, were made available to all students at the beginning of each semester. In addition, the material available on web contained:

- A set of problems at the end of each chapter.

- Methodologies and step-by-step solutions to the problems.

- Powerpoint slides that were used during class lectures and discussions.

- Reference material that students could get or access through library.

- Software needed to solve some of the problems

All students had access to the above material but only AL students could access streaming videos of lectures. A textbook was also required in the course. 
In general, there weren't any major issues related to teaching except the amount of effort needed to develop the course material. Access to our server was readily available 24/7 and could accommodate a large number of login at any given time. There were some issues regarding the quality of audio on the streaming video but the issues had to do with the movement of the instructor. The concern was resolved during the very first semester when the first course was offered to students who registered for the AL section.

\subsection{Communications related issues}

The students were provided with schedules of on-campus office hour for on-campus students and virtual office hour for AL students. The virtual office hour schedule was determined in consultation with the asynchronous learners. It provided an excellent opportunity for AL students to seek academic assistance from the instructor and to network amongst themselves. While the on-campus students, by the very presence of being in classroom before the start of each class, are exposed to and, at times, induced to network and discuss course related matters, the AL students did not appear to latch on to that opportunity.

In addition, all students could post their questions on the website or email them to the instructor. Although the response time was made clear, it appeared, at least during the early part of the course, a few of the AL students expected a quick response to their questions.

Most of the AL students submitted their work on the secure website for the course. A major problem encountered with such an approach in a graduate level, technical course is the volume of work and printing of the submitted material. It not only stressed the system but also required frequent attention due to shuffling of printed pages and reports. This may not be the case in some other courses but higher level technical courses may need to address this issue.

\subsection{Learning related issues}

The learning related issues with these courses were not any different than the on-campus courses except that the on-campus students, through interactions amongst themselves, tend address some their learning problems. This was, generally, not the case with AL students. Other issues related to learning were:

- The varying background of graduates in the first course required more assistance and communication during the first part of the course.

- The expectation that the instructor would respond to AL students' questions promptly, on a daily basis.

- The willingness of AL students to participate in virtual office hours except before assignment due date or test date created more learning difficulties, at least in the beginning of the course.

- Problems related to learning and application of the knowledge was more related to individual AL student's discipline and time management.

\section{Assessment of students' performance}

Students in both the courses were evaluated on a continual basis using homework assignments, project and tests. The simulation project was designed to test students' knowledge and understanding of course topics and required their use of computer technology. Except for the 
tests, which were timed, ample time was given to all students to work on their homework assignments and project. Feedback was provided to students in a timely manner. Table 1 shows the distribution of points for categories that were used to evaluate the overall performance in the course.

The on-campus and AL students' scores in all three categories were analyzed and compared for differences and trends. The results are shown in Tables 2 and 3.

Table 1. Point distribution in categories

\begin{tabular}{|l|c|c|}
\hline \multicolumn{1}{|c|}{ Graded Item } & Points, Course \#1 & Points, Course \#2 \\
\hline Assignments & 10 & 15 \\
\hline Project & 30 & 30 \\
\hline Two Tests & 60 & 55 \\
\hline Total & 100 & 100 \\
\hline
\end{tabular}

Analysis of the information reveals that, on average, there was not much difference between the performance of campus and AL students. In fact, the averages for the AL students in course 2 were better than the corresponding values for the campus students.

Table 2. Comparison of students' performance in course 1

\begin{tabular}{|l|c|c|c|c|c|c|c|c|}
\hline & \multicolumn{2}{|c|}{ Homework } & \multicolumn{2}{c|}{ Project } & \multicolumn{2}{c|}{ Tests } & \multicolumn{2}{c|}{ Overall } \\
\hline & $\begin{array}{c}\text { Campus } \\
\mathrm{N}=86\end{array}$ & $\begin{array}{c}\mathrm{AL} \\
\mathrm{N}=38\end{array}$ & $\begin{array}{c}\text { Campus } \\
\mathrm{N}=86\end{array}$ & $\begin{array}{c}\mathrm{AL} \\
\mathrm{N}=38\end{array}$ & $\begin{array}{c}\text { Campus } \\
\mathrm{N}=86\end{array}$ & $\begin{array}{c}\text { AL } \\
\mathrm{N}=38\end{array}$ & $\begin{array}{c}\text { Campus } \\
\mathrm{N}=86\end{array}$ & $\begin{array}{c}\mathrm{AL} \\
\mathrm{N}=38\end{array}$ \\
\hline Average & 66.7 & 69.7 & 71.1 & 75.5 & 68.7 & 69.1 & 68.9 & 70.1 \\
\hline Std Dev & 15.7 & 17.8 & 13.0 & 16.7 & 13.2 & 14.9 & 10.7 & 14.3 \\
\hline COV,\% & 23.5 & 25.5 & 18.3 & 22.1 & 19.2 & 21.6 & 15.5 & 20.3 \\
\hline
\end{tabular}

But the standard deviation of scores for AL students in course 1, in almost all categories, was higher than that for the campus students. The wider distribution of scores for the AL students resulted in larger standard deviation as well as larger values of Coefficient of Variation (COV) in performance. Some of the outliers in the AL group were responsible for bringing the average values up while, at the same time, creating larger deviation.

Observations reveal three areas that have caused larger deviation and higher values of COV in AL students' performance compared to campus students:

- Prior academic background and adequate fulfillment of prerequisites in course 1.

- Although these were not quite self-paced courses, they required self-discipline.

- Time management on the part of AL students. Although this was true for all students, the interaction amongst campus students provided enough urgency to handle material in a timely fashion. This aspect was absent in more AL students than the campus students.

The average performance of AL students in the second course was even better than the campus students. Course 1 is a prerequisite for the follow-up course 2 and most of the students in that course had taken the first course at our institution. Hence, they were better tuned to the learning process and expectations than their preparation course 1. Except for the tests, the COV between the two groups were closer than in course 1. 
Table 3. Comparison of students' performance in course 2

\begin{tabular}{|l|c|c|c|c|c|c|c|c|}
\hline & \multicolumn{2}{|c|}{ Homework } & \multicolumn{2}{c|}{ Project } & \multicolumn{2}{c|}{ Tests } & \multicolumn{2}{c|}{ Overall } \\
\hline & Campus & $\mathrm{AL}$ & Campus & $\mathrm{AL}$ & Campus & $\mathrm{AL}$ & Campus & $\mathrm{AL}$ \\
& $\mathrm{N}=20$ & $\mathrm{~N}=12$ & $\mathrm{~N}=20$ & $\mathrm{~N}=12$ & $\mathrm{~N}=20$ & $\mathrm{~N}=12$ & $\mathrm{~N}=20$ & $\mathrm{~N}=12$ \\
\hline Average & 65.4 & 76.6 & 62.4 & 69.7 & 72.1 & 73.3 & 68.2 & 72.9 \\
\hline Std Dev & 8.7 & 10.2 & 12.6 & 12.5 & 5.8 & 10.6 & 7.5 & 9.4 \\
\hline COV, \% & 13.3 & 13.3 & 20.2 & 17.9 & 8.0 & 14.5 & 11.0 & 12.9 \\
\hline
\end{tabular}

Three major reasons contributed to closeness of values:

- Most, if not all, had keen interest in the subject matter and were motivated.

- A significant number of students in the second course had gone through the first course at our campus and were well grounded in the prerequisite material.

- They were better disciplined and were better at managing their time on course material. This was evident by comparing the time devoted to communication between the AL students and the instructor.

\section{Conclusions}

The report provides a comparison of performance and learning experience of campus students and AL students in a set of courses. The results of the study show that, on average, AL students performed as well as the campus students but the spread in their performance level was larger than the campus students. Self-discipline and time management were two major factors that impacted performance of AL students more than the campus students. This is not very surprising since AL students, in all likelihood, have more severe time constraints than the campus students. Both the groups were well-equipped to handle computer technology for projects and assignments. Observations made during the time period of interest revealed that the instructor had to devote more time to cater to academic needs of AL students than the campus students. This was particularly crucial when dealing with technical and math based discussion because of technical limitations.

\section{References}

1. Chapman, D. D. (2005), Building an Evaluation Plan for Fully Online Degree Programs.

2. Indiana University Report (2004), Technology as a Lever - Developing Guidelines for Good Practice in Education.

3. Johnson, S. D., Aragon, S. R., Shaik, N. and Palma-Rivas, N. (2000), Comparative Analysis of Learner Satisfaction and Learning Outcomes in Online and Face-to-Face Learning Environments, J of Interactive Learning Research, 11(1), 29-49.

4. Varde, N. and Fogler, H. S. (2002), Asynchronous Learning of Chemical Reaction Engineering, e-Technologies in Engineering Education, ECI Symposium Series, Vol P1.

5. Varde, K. S. (2005), Development of a DL Course and Comparison of Students' Performance, Paper presented at Exploring Innovation in Education and Research, Tainan, 2005. 